\begin{tabular}{|c|c|c|}
\hline \multirow{3}{*}{$\begin{array}{r}\text { Case Reports in } \\
\text { Gastroenterology }\end{array}$} & \multirow{2}{*}{\multicolumn{2}{|c|}{ Case Rep Gastroenterol 2013;7:455-461 }} \\
\hline & & \\
\hline & $\begin{array}{l}\text { DOI: 10.1159/000355940 } \\
\text { Published online: October 15, } 2013\end{array}$ & $\begin{array}{l}\text { (c) } 2013 \text { S. Karger AG, Basel } \\
\text { 1662-0631/13/0073-0455 } \$ 38.00 / 0 \\
\text { www.karger.com/crg }\end{array}$ \\
\hline & \multicolumn{2}{|c|}{$\begin{array}{l}\text { This is an Open Access article licensed under the terms of the Creative Commons } \\
\text { Attribution-NonCommercial } 3.0 \text { Unported license (CC BY-NC) (www.karger.com/OA } \\
\text { license), applicable to the online version of the article only. Distribution permitted for non } \\
\text { commercial purposes only. }\end{array}$} \\
\hline
\end{tabular}

\title{
Cauda Equina Syndrome Secondary to Complicated Diverticulitis
}

\author{
M. ter Horst ${ }^{a}$ M.A.W. Stam ${ }^{c} \quad$ D.E. Bouman ${ }^{b} \quad$ J.M. Klaase ${ }^{a}$ \\ Departments of ${ }^{a}$ Surgery and ${ }^{b}$ Radiology, Medisch Spectrum Twente, Enschede, and \\ 'Department of Surgery, Meander Medisch Centrum, Amersfoort, The Netherlands
}

\section{Key Words}

Complicated diverticulitis · Colonic diverticulitis · Sigmoid · Fistula · Cauda equina syndrome

\begin{abstract}
A 58-year-old woman presented to the emergency department with cauda equina syndrome and sepsis. The symptoms were attributed to a complicated episode of sigmoid diverticulitis. MRI showed that the diverticulitis had caused an intra-abdominal fistula to a presacrally localized abscess expanding into the spinal canal, compressing the cauda equina nerves. Although Hartmann's procedure was performed, the neurological symptoms persisted, causing the patient to remain partially paraplegic. This case report illustrates that cauda equina syndrome is a condition that can also be caused by intra-abdominal pathology such as diverticulitis.

(c) 2013 S. Karger AG, Basel
\end{abstract}

\section{Introduction}

In light of its rising incidence, diverticulitis is one of the most common gastrointestinal tract infections in Western countries [1]. Colonic diverticula are bulging pouch-like herniations through the wall of the colon at weak spots in the muscular layer, where the bloodsupplying arteries enter the intestinal wall [2]. The sigmoid colon is prone to diverticula. It is hypothesized that this is due to the increased pressure in this part of the colon [3]. Diverticulosis remains asymptomatic in $70 \%$ of patients, however about $10-25 \%$ of patients develop diverticulitis [4-6]. The etiology of diverticulitis has not entirely been cleared up yet, but it is commonly accepted that diverticulitis is the result of a diverticular obstruction by fecal content. The extent of the infection can vary from local extraluminal pericolic infection to generalized peritonitis [3]. 
ter Horst et al.: Cauda Equina Syndrome Secondary to Complicated Diverticulitis

Patients suffering from diverticulitis usually complain of left lower quadrant abdominal pain and alterations in their defecation pattern. Fever, chills and urinary urgency are common as well [3]. The diagnosis is confirmed by ultrasound or CT scan of the abdomen, depending on the severity of the initial presentation, patient-related factors such as BMI, and experience of the radiologist. Diverticulitis is generally classified using the modified Hinchey classification, which is shown in table 1 [7]. Patients with uncomplicated diverticulitis (Hinchey 0 , Ia and Ib) can mostly be treated with bowel rest on an outpatient basis. Only patients who have significant pain and signs of localized peritonitis should be hospitalized. While hospitalized, intravenous antibiotics are indicated in case of sepsis or otherwise complicated diverticulitis. One speaks of complicated diverticulitis if the inflammatory process is associated with the development of a large pelvic abscess, fistula, obstruction or colonic perforation causing purulent or fecal peritonitis. Emergency surgery is indicated in patients who have purulent or fecal peritonitis. Otherwise complicated diverticulitis is generally considered as an indication for elective colon resection in a later stage [8, 9].

This case report describes the history of a patient who developed cauda equina syndrome secondary to complicated diverticulitis with the formation of a fistula to the spinal cord.

\section{Case Report}

A 58-year-old woman with no past medical history presented to the emergency department with progressive lumbar back pain radiating to her left leg. The pain radiated throughout the entire left leg. She also experienced a sensation of numbness in her lower left leg and foot. These symptoms had been progressing for the past 3 weeks. She had developed a gait disorder 5 days prior to presentation, which she assigned to a lack of coordination in her left foot. She also complained of urine and bowel incontinence. There was no abdominal pain. She only mentioned having had a fever 1 day prior to these complaints. During the preceding months she had lost $11 \mathrm{~kg}$ of body weight.

On physical examination the patient appeared ill. Vital signs showed a septic profile with a body temperature of $38.8^{\circ} \mathrm{C}$. Neurological examination of the lower limbs revealed decreased strength in her left leg, with a strength of Medical Research Council (MRC) 3/5 in the iliopsoas, MRC 4/5 in the tibialis anterior, and MRC 4+/5 in the gastrocnemius. Strength in the right leg was entirely normal. There was normal sensation in the saddle area and the perianal area, as well as a normal anal sphincter tone. The straight leg test showed a positive Lasègue sign on the left side. Abdominal examination showed a soft, non-tender abdomen.

Laboratory tests showed leukocytosis and an elevated C-reactive protein level (table 2). Initially, urinalysis could not be performed because the patient was unable to urinate. On catheterization, however, she had a urine retention of 1,300 $\mathrm{ml}$. A chest and lumbar spine X-ray were taken, which both showed no abnormalities.

The patient's septic condition worsened in the emergency department with a high-grade fever $\left(40.9^{\circ} \mathrm{C}\right)$. Antibiotic therapy was started with Amoxicillin/Clavulanate and the patient was transferred to our center's intensive care unit.

MRI of the spinal canal showed a fistula from the sigmoid colon to a presacrally localized abscess, most likely secondary to diverticulitis (fig. 1). The abscess had expanded into the spinal canal, the paravertebral soft tissue on the left side, and the erector spinae muscles on both sides. Also, there were signs of sacral osteomyelitis and diffuse meningeal staining of the conus medullaris and the cauda equina. The presence of an epidural abscess could not be confirmed (fig. 2). An additional chest/abdominal CT scan showed pleural fluid on both 
ter Horst et al.: Cauda Equina Syndrome Secondary to Complicated Diverticulitis

sides. There were multiple fluid and air collections located presacrally and retroperitoneally as well as along the psoas muscle. There was air in the spinal canal and the back muscles. There were no signs of spondylodiscitis (fig. 3).

Consequently, Hartmann's procedure was performed as treatment for the diverticulitis. Multiple intra-abdominal abscesses were drained peroperatively. Two intra-abdominal drains were placed to maintain postoperative drainage of the abscess pockets. Postoperative management consisted of broad-spectrum antibiotics and therapeutic heparin for a thrombus in the left iliac vein. On postoperative day one the patient was extubated, and on postoperative day four she was transferred to the gastrointestinal surgery ward. She remained hemodynamically normal and her stoma production started. The neurological symptoms did not resolve completely during her stay. Eventually, the patient was returned to her primary care center 2 weeks after admission to our hospital. There she was enrolled in an intensive rehabilitation program for her persisting neurological symptoms.

\section{Discussion}

This case report describes the history of a patient suffering from an episode of diverticulitis complicated by fistula formation to the spinal cord. Fistulas, pelvic abscesses, obstruction and perforation causing peritonitis are some of the more serious complications of diverticulitis. Fistula formation accounts for up to $20 \%$ of all surgically treated cases of diverticular disease. The sigmoid is the most commonly affected segment of the colon by diverticulitis, therefore fistulas usually arise from this part of the colon. As a result of their close anatomy, colovesical fistulas (65\%) and colovaginal fistulas (25\%) are the most frequently occurring fistulas. Colovesical fistulas are more common in men than in women because the uterus usually shields the bladder from being penetrated by the fistula $[3,10]$. However, a fistula can form to whichever organ the inflammatory process tracks, and has been described in many unexpected sites, such as the seminal vesicle [11]. A colospinal fistula as in our patient has, to our knowledge, never been described.

Diverticular fistulas generally do not close spontaneously. However, emergency surgery is rarely indicated in patients with this condition. The goal of the initial treatment of a fistula caused by diverticulitis is to control the infection and reduce the associated colonic inflammation. Subsequently, an elective surgical procedure is performed to serve as a definitive treatment of the fistula. Preferably, a colonoscopy should be done prior to surgery in order to rule out colon cancer as a cause of the fistula. Fistulas caused by diverticulitis can usually be treated by combined resection of the fistula and sigmoid colon, after which an anastomosis is created between the descending colon and the rectum. However, when a patient's condition is too critical to tolerate a so-called cooling-off period, as in our patient, urgent surgical resection is necessary to relieve symptoms. The extent of the inflammatory process in these cases determines whether a primary anastomosis can be made or not $[3,8$, 9].

\section{Conclusion}

To our knowledge, this is the first case ever described of cauda equina syndrome caused by a fistula arising from complicated diverticulitis. Although it is known that $10-25 \%$ of patients with diverticulosis develop diverticulitis and a subsequent $10 \%$ of those patients will suffer from a complicated disease course, the critical condition in which this patient 
ter Horst et al.: Cauda Equina Syndrome Secondary to Complicated Diverticulitis

presented is exceptional. Taking this case into consideration, we also recommend that intraabdominal pathology should always have a place in the differential diagnosis of acute cauda equina syndrome.

\section{References}

1 Etzioni DA, Mack TM, Beart RW Jr, Kaiser AM: Diverticulitis in the United States: 1998-2005: changing patterns of disease and treatment. Ann Surg 2009;249:210-217.

-2 Meyers MA, Alonso DR, Gray GF, Baer JW: Pathogenesis of bleeding colonic diverticulosis. Gastroenterology 1976;71:577-583.

3 Townsend C, Beauchamp R, Evers B: Sabiston Textbook of Surgery, ed 19. Philadelphia, Saunders, 2012. Stollman N, Raskin JB: Diverticular disease of the colon. Lancet 2004;363:631-639. Jacobs DO: Clinical practice. Diverticulitis. N Engl J Med 2007;357:2057-2066.

Sheth AA, Longo W, Floch MH: Diverticular disease and diverticulitis. Am J Gastroenterol 2008;103:15501556.

7 Kaiser AM, Jiang JK, Lake JP, Ault G, Artinyan A, Gonzalez-Ruiz C, Essani R, Beart RW Jr: The management of complicated diverticulitis and the role of computed tomography. Am J Gastroenterol 2005;100:910-917.

-8 Rafferty J, Shellito P, Hyman NH, Buie WD; Standards Committee of American Society of Colon and Rectal Surgeons: Practice parameters for sigmoid diverticulitis. Dis Colon Rectum 2006;49:939-944.

-9 Janes S, Meagher A, Frizelle FA: Elective surgery after acute diverticulitis. Br J Surg 2005;92:133-142.

$\rightarrow 10$ Woods RJ, Lavery IC, Fazio VW, Jagelman DG, Weakley FL: Internal fistulas in diverticular disease. Dis Colon Rectum 1988;31:591-596.

11 LaSpina M, Facklis K, Posalski I, Fleshner P: Coloseminal vesicle fistula: report of a case and review of the literature. Dis Colon Rectum 2006;49:1791-1793.

Table 1. The modified Hinchey classification

\begin{tabular}{ll}
\hline 0 & mild clinical diverticulitis \\
Ia & confined pericolic inflammation - phlegmon \\
Ib & confined pericolic abscess \\
II & pelvic, distant intra-abdominal or retroperitoneal abscess \\
III & generalized purulent peritonitis \\
IV & fecal peritonitis/intestinal obstruction \\
Fistula & colovesical/colovaginal/coloenteric/colocutaneous \\
Obstruction & large and/or small bowel obstruction \\
\hline
\end{tabular}




\section{Case Reports in \\ Gastroenterology}

\begin{tabular}{l|l}
\hline \multicolumn{2}{l}{ Case Rep Gastroenterol 2013;7:455-461 } \\
\hline DOI: $10.1159 / 000355940$ & $\begin{array}{l}\text { C 2013 S. Karger AG, Basel } \\
\text { www.karger.com/crg }\end{array}$ \\
\hline
\end{tabular}

ter Horst et al.: Cauda Equina Syndrome Secondary to Complicated Diverticulitis

Table 2. Laboratory results

\begin{tabular}{lll}
\hline Component & Result & Reference range \\
\hline $\mathrm{Hb}$ & 6.7 & $7.5-10 \mathrm{mmol} / \mathrm{l}$ \\
$\mathrm{Ht}$ & 0.32 & $0.36-0.47 \mathrm{l} / \mathrm{l}$ \\
$\mathrm{MCV}$ & 94 & $90-100 \mathrm{fl}$ \\
$\mathrm{WCC}$ & 15.4 & $4.0-10.0 \times 10^{9} / \mathrm{l}$ \\
Platelets & 295 & $150-400 \times 10^{9} / \mathrm{l}$ \\
INR & 1.2 & $0.9-1.1$ \\
CRP & 317 & $<10 \mathrm{mg} / \mathrm{l}$ \\
$\mathrm{K}$ & 4.2 & $3.5-5.0 \mathrm{mmol} / \mathrm{l}$ \\
Na & 137 & $135-145 \mathrm{mmol} / \mathrm{l}$ \\
Urea & 18.2 & $2.5-6.4 \mathrm{mmol} / \mathrm{l}$ \\
Creatinine & 106 & $45-80 \mu \mathrm{mol} / \mathrm{l}$ \\
eGFR (MDRD) & 46 & $>90 \mathrm{ml} / \mathrm{min}$ \\
Glucose & 8.4 & $4.0-6.4 \mathrm{mmol} / \mathrm{l}$ \\
GGT & 24 & $<35 \mathrm{U} / \mathrm{l}$ \\
ALP & 88 & $<125 \mathrm{U} / \mathrm{l}$ \\
ALT & 13 & $<40 \mathrm{U} / \mathrm{l}$ \\
AST & 25 & $<45 \mathrm{U} / \mathrm{l}$ \\
LDH & 149 & $135-225 \mathrm{U} / \mathrm{l}$ \\
CK & 83 & $<170 \mathrm{U} / \mathrm{l}$ \\
Total protein & 77 & $60-80 \mathrm{~g} / \mathrm{l}$ \\
Albumin & 26.9 & $35-55 \mathrm{~g} / \mathrm{l}$ \\
\hline
\end{tabular}

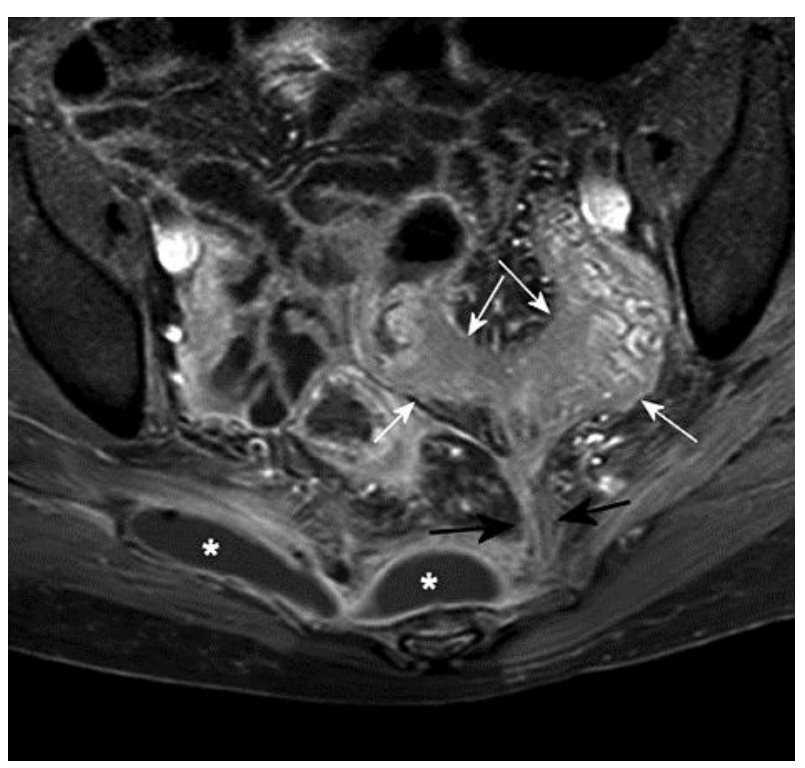

Fig. 1. T1-weighted MRI after gadolinium administration. A fistula (black arrows) from a sigmoid diverticulitis (white arrows) to a presacrally localized abscess (white asterisks) is shown. 
ter Horst et al.: Cauda Equina Syndrome Secondary to Complicated Diverticulitis

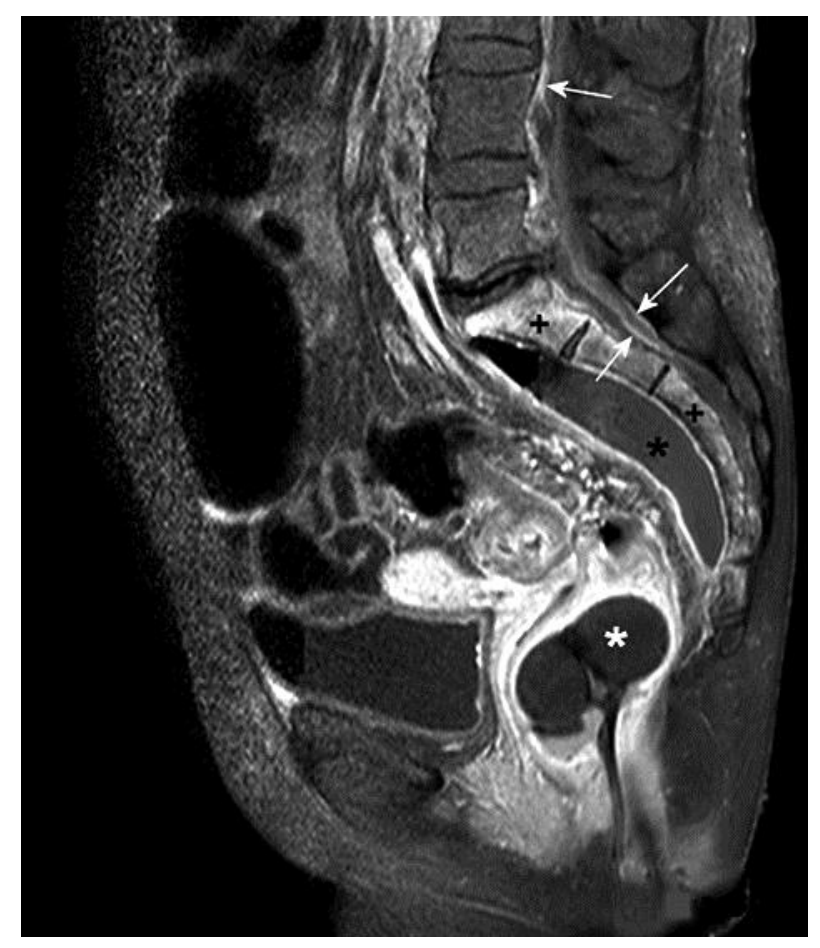

Fig. 2. T1-weighted MRI after gadolinium administration. Shown is the presacrally localized abscess (black asterisk) with complete staining of the border. There is diffuse staining of the sacral bone (plus symbols) without involvement of the intervertebral discs, which is suggestive of osteomyelitis. Furthermore, there is diffuse meningeal staining (white arrows) of the conus medullaris and cauda equina. A rectal device (white asterisk) is in situ. 


\begin{tabular}{|c|c|c|}
\hline \multirow{2}{*}{$\begin{array}{l}\text { Case Reports in } \\
\text { Gastroenterology }\end{array}$} & \multicolumn{2}{|c|}{ Case Rep Gastroenterol 2013;7:455-461 } \\
\hline & DOI: $10.1159 / 000355940$ & $\begin{array}{l}\text { (c) } 2013 \text { S. Karger AG, Basel } \\
\text { www.karger.com/crg }\end{array}$ \\
\hline
\end{tabular}

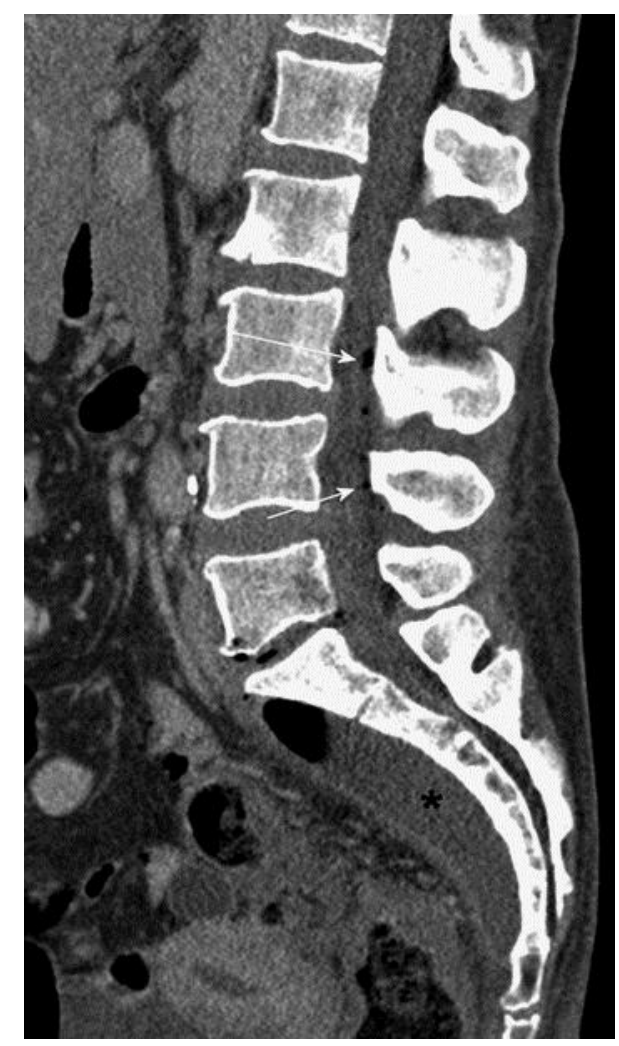

Fig. 3. CT scan of the abdomen showing multiple intraspinal fluid and air collections (white arrows) and a presacral abscess (black asterisk). 